For those who decline behavioural and cognitive therapy or who do not respond fully, the treatment of choice is antiobsessional drugs, either potent or selective serotonin reuptake inhibitors. ${ }^{10}$ About $60 \%$ of patients will respond, with on average a halving of symptoms even in the absence of depression. Patients may need to be given the highest tolerable dose for up to 12 weeks to achieve the full response. In patients with a comorbid tic disorder the addition of a neuroleptic drug may improve the outcome. ${ }^{11}$ Stopping treatment frequently leads to relapse. To reduce the risk of relapse patients should continue treatment long term or be treated with a combination of drugs, behaviour therapy, and cognitive therapy. Selective serotonin reuptake inhibitors have some troublesome side effects, such as anorgasmia. These may be acceptable in the short term treatment of depression but not when treating a chronic condition such as obsessive compulsive disorder.

It is not yet known which patients will respond to which treatments or whether there is a hard core of patients who cannot yet be fully treated. For some patients, obsessive compulsive disorder remains a chronic handicap as severe as schizophrenia.

Dr Veale is a committee member of Obsessive Action.

Obsessive Action (PO Box 6097, London W2 1WZ, tel 0181991

9585) is a new charity set up to educate the public and health professionals about obsessive compulsive disorder, to provide a network of support for sufferers, and to raise funds for research. Triumph over Phobia (PO Box 1831, Bath BA1 3YX, tel 01225 330353 ) is an established charity of lay volunteers who teach patients with obsessive compulsive disorder and phobias the principles of self management.

DAVID VEALE

Grovelands Priory Hospital,

London N14 6RA

1 Scanlon TJ, Luben RN, Scanlon FX, Singleton N. Is Friday the 13th bad for your health? BMO 1993;307:1584-6.

Frost RO, Krause MS, McHahon MJ, Peppe J, Evans M. Compulsivity and superstitiousness. Behav Res Ther 1993;31:423-5.

3 Salkovskis PM, Richards C, Forrester E. The relationship between obsessional problems and intrusive thoughts. Behavioural and Cognitive Psychotherapy 1995;23:281-99.

4 Regier DA, Narrow WS, Rae DS, Manderscheid RW, Locke BZ, Goodwin FK. The de facto US mental and addictive disorders service system: epidemiological catchment area prospective 1-year prevalence rates of disorders and services. Arch Gen Psychiatry 1993;50:85-94.

5 Tallis F. Obsessive compulsive disorder. A cognitive and neuropsychological perspective. Chichester: Wiley, 1995.

6 Robinson D, Wu H, Munne R, Ashtari M, Alvir JM, Lerner G, et al. Reduced caudate nucleus volume in obsessive-compulsive disorder. Arch Gen Psychiatry 1995;52:393-8.

7 Baxter LR, Schwartz JM, Bergman KS, Szuba MP. Caudate glucose metabolic rate changes with both drug and behavior therapy for obsessive-compulsive disorder. Arch Gen Psychiatry 1992;49:681-9.

8 Foa EB, Emmelkamp PMG. Failures in behavior therapy. New York: Wiley, 1983:10-34.

9 Van Oppen P, de Haan E, van Balkom AJ, Spinhoven P, Hoogduin K, van Dyck R. Cognitive therapy and exposure in vivo in the treatment of obsessive compulsive disorder. Behav Res Ther 1995;33:379-90.

10 Wood A. Pharmacotherapy of OCD. Fournal of Serotonin Research 1995;1(suppl 1):63-76.

11 McDougle CJ, Goodman WK, Leckman JF, Lee NC, Heninger GR, Price L. Haloperidol addition in fluvoxamine refractory obsessive compulsive disorder. Arch Gen Psychiatry 1994;51:302-8.

\title{
Domestic violence against women
}

\section{Needs action from doctors and the health service}

Two abused women were recently freed from prison in Britain. Emma Humphreys and Sara Thornton had previously been found guilty of murdering violent partners and had received mandatory life sentences. Humphreys's conviction was quashed by judges in the Court of Appeal, whose ruling recognised the months of cruelty she had experienced from her boyfriend, including beatings and rapes. Thornton's case is pending appeal. In future cases cumulative abuse will be seen as possible provocation, allowing a charge of manslaughter rather than murder.

The violence that both of these women suffered is common. Mooney found that $27 \%$ of women surveyed in north London had experienced physical injury from their partners or former partners, while $37 \%$ had experienced mental cruelty and $23 \%$ had been raped. ${ }^{1}$ In the 1992 British crime survey, $11 \%$ of women who had lived with a partner reported physical violence against them in their relationship. ${ }^{2}$ The continuing and repeated nature of domestic violence is also well established. Eight per cent of women in the north London survey had been injured during the previous 12 months, of whom more than a quarter had been injured at least six times during the year. ${ }^{1}$ A study of women in refuges in England and Wales showed that almost three quarters had put up with violence for three or more years. ${ }^{3}$

Domestic violence carries a risk of death: $40-45 \%$ of female homicide victims in England and Wales are killed by present or former partners. ${ }^{4}$ By contrast, only $6 \%$ of male homicide victims are killed by their spouse or a lover. Humphreys and Thornton might themselves have been killed by their partners. As well as injuries, doctors should be aware of other features that are associated with domestic violence. Mental health and rape are more common among women who have been victims of physical abuse, ${ }^{5}$ as are sexual assault health problems, particularly anxiety, depression, and suicide attempts. ${ }^{6}$ Battering may increase during pregnancy, ${ }^{7}$ and women experiencing domestic violence are reported as having an increased rate of miscarriage and low birthweight babies. ${ }^{89}$ Rates of substance misuse rise considerably after battering begins, ${ }^{6}$ and there is a high risk of child abuse among the children of abused women. ${ }^{5}$ Women in ethnic minority communities who experience domestic violence face a double jeopardy, since the difficulties of securing help may be compounded by racism. ${ }^{10}$

\section{Health services lack commitment}

The release of Humphreys and Thornton may indicate that the legal system has adopted a more positive attitude towards women experiencing domestic violence, but has there been progress in other areas? In particular, are doctors beginning to take on the crucial role suggested in an editorial in the $B M \mathcal{F}$ in 1989 ? $^{11}$ The response to domestic violence from the police and social services has improved since the publication of an influential review by the Home Office, ${ }^{12}$ but on the whole, health services have not shown a similar commitment. This is despite the report in 1992 of a national interagency working party on domestic violence, which made important proposals in relation to health care and other areas. ${ }^{9}$ The report recommended that each group of health professionals should prepare and agree guidelines for good practice in identifying and caring for victims of domestic violence and that all accident and emergency staff and all members of the primary health care team should receive specific training about domestic violence, as well as information about resources for victims. 
Guidelines from the American Medical Association recommend that doctors should routinely ask all women direct questions about abuse. ${ }^{13}$ The need for this stems largely from the absence of specific indicators of violence that could be useful in a clinical setting. ${ }^{14}$ In addition, many women do not spontaneously disclose that they are being battered, and doctors may feel inhibited about asking. When a protocol for detecting injuries caused by battering was introduced in an emergency department in the United States the identification of battered women among women presenting with trauma rose from $6 \%$ to $30 \%{ }^{15}$ The Joint Commission on the Accreditation of Healthcare Organisations now requires all emergency and ambulatory care services in the United States to adopt written policies and procedures relating to adult victims of abuse. ${ }^{16}$ Healthcare guidelines exist in Britain, such as those published by the Royal College of General Practitioners ${ }^{17}$ and unpublished guidelines from the British Association of Accident and Emergency Medicine, but they require implementation.

The recent re-emergence of domestic violence into the public domain should provoke action in the health service. Purchasers have a key role in ensuring that providers implement guidelines for identifying and caring for victims of domestic violence. A Home Office circular on interagency working promotes further development of domestic violence forums, although it does not offer any new resources. ${ }^{18} \mathrm{But}$ guidelines alone are not enough. A comprehensive document produced by the Department of Health and Social Services and Northern Ireland Office ${ }^{19}$ sets out four aims in tackling domestic violence: to heighten awareness of domestic violence, highlighting domestic assault as a crime; to improve services for victims; to challenge perpetrators' attitudes and behaviour; and to improve the information base. Doctors and other health care professionals must contribute to each of these aims.

Funding: None.

Conflict of interest: None.

JO RICHARDSON Research fellow GENE FEDER Senior Lecturer

Joint Academic Department of General Practice and Primary Care,

The Medical Colleges of St Bartholomew's and the Royal London Hospitals, London EC1M 6BQ

1 Mooney J. The hidden figure: domestic violence in North London. London: Islington Council, 1993. 2 Mirrlees-Black C. Estimating the extent of domestic violence: findings from the 1992 BCS. London: Home Office Research and Planning Unit, 1995. (Home Office research and statistics department Home Office Research and
research bulletin No 37 .)

3 Pahl J. Health professionals and violence against women. In: Kingston P, Penhale B, eds. Family violence and the caring professions. London: Macmillan, 1995:127-48.

4 Home Office. Domestic violence factsheet. London: Home Office, 1995.

5 Plichta S. The effects of woman abuse on health care utilisation and health status: a literature review. Womens Health Issues 1992;2:154-63.

6 Stark E, Flitcraft AH. Spouse abuse. In: Rosenberg M, Mercy J, eds. Violence in America: a public health approach. New York: Oxford University Press, 1991.

7 McFarlane J. Violence during teen pregnancy: health consequences for mother and child. In: Levy B, ed. Dating violence-young women in danger. Seattle: Seal Press, 1991:136-41.

8 Bullock LF, McFarlane J. The birth-weight/battering connection. Am f Nurs 1989;89:1 153-5.

9 Start E, Flitcraft A, Frazier W. Medicine and patriarchal violence: the social construction of a "private" event. Int $f$ Health Serv 1979;9:461-93

0 Victim Support. Domestic violence. Report of a national inter-agency working party. London: Victim Support, 1992.

11 McIllwaine G. Women victims of domestic violence. BMF 1989;299:995-6.

12 Smith LJF. Domestic violence: an overview of the literature. London: HMSO, 1989.

2 Smith LJF. Domestic violence: an overview of the literature. London: HMSO, 1989. Fam Med 1992:1:39-47.

4 Richardson J, Feder G. Domestic violence-a hidden problem for general practice (in press).

15 McLeer SV, Anwar RAH, Herman S, Maquiling K. Education is not enough: a systems failure in protecting battered women. Ann Emerg Med 1989;18:651-3.

16 Sheridan DJ, Taylor WK. Developing hospital-based domestic violence programs, protocols, policies and procedures. $A$ WHONN'S-Clin-Issues-Perinat-Womens-Health-Nurs 1993;4: 471-82.

17 Heath I. Domestic violence: the general practitioner's role. Royal College of General Practitioners members reference book 1992. London: Sabrecrown, 1992.

18 Home Office. Inter-agency co-ordination to tackle domestic violence. London: Home Office, 1995. (Home Office circular.)

19 Department of Health and Social Services and Northern Ireland Office. Tackling domestic violence. A policy for Northern Ireland. Belfast: Department of Health and Social Services and Northern Ireland Office, 1995.

\section{Only doing my duty?}

\section{The GMC's new guidance on doctors' professional and ethical duties}

This week, the General Medical Council publishes its guidance to doctors on their professional duties.' Previously, doctors seeking clarification about ethical dilemmas would have turned to the Council's "Blue Book"; a thin volume from which it was sometimes difficult to extract user-friendly information. This may have contributed to a perception of the General Medical Council as a grim institution filled with medical grandees handing out discipline like a Victorian grandparent.

The "Blue Book" placed little emphasis on relationships in health care and seemed to make ethical dilemmas somewhat peripheral to good practice. By contrast, in Duties of a Doctor good relationships with patients and observance of ethical obligations become essential elements of medical practice. This is an important development; by putting ethics and the doctor patient relationship at the heart of good practice, a doctor cannot act professionally if also simultaneously acting unethically. Professional relations between colleagues also receive special attention. Most doctors will already know that they are now duty bound to report colleagues who appear to be practising incompetently. For the first time too, there is express statement forbidding discrimination against each other on any grounds, including ethnicity and sex.

Instead of a list of possible "offences" and criteria for "fitness to practise" the new guidance emphasises care and "duties." The new guidance states that doctors should make the "care of [your] patient your first concern." Professional competence is obviously an essential of good practice, as is the need to maintain that competence, but what might be called the "technoclinical" sphere of health care is recognised as being only one dimension of good practice. Experienced (and wiser) doctors, nurses and patients have always known this, but to have it formally emphasised in a document of this kind is most welcome.

In fact the document is rather less formal than its predecessor. It comes as four booklets: one a general statement about professional duties; the other three dealing with confidentiality, HIV/AIDS, and advertising. Its tone is direct, addressing the doctor as "you"; the layout is easier to read, making the messages clearer, although a summary page at the end of each booklet would have been as helpful as the index supplied.

The document provides ethical guidance based on core principles, and not a code of ethics. There are therefore gaps in the coverage of many common ethical dilemmas. For example, a difficulty faced by all doctors is the scope of their duties to third parties. The issue of confidentiality is covered to some extent but there are other aspects to be addressed. Different types of doctor-patient relationships give rise to 